\title{
BMX compared with ordinary bicycle accidents
}

\author{
C M ILLINGWORTH
}

Accident and Emergency Department, Children's Hospital, Sheffield

SUMMARY Three hundred new cases of bicycle accidents were seen in the accident and emergency department in 60 consecutive days. Fifty six per cent were related to ordinary cycles and $44 \%$ to BMX cycles. Significantly more children on BMX cycles were boys $(94 \% v 76 \%$ on ordinary cycles). Those on BMX cycles were somewhat older and more had had previous accidents.

By means of a proforma we investigated the nature and causes of the accidents, recorded the type of injury, and compared accidents on the two groups of bicycles. Forty children had fractures and the incidence on BMX machines was almost twice that on conventional bicycles as were serious injuries and admissions to hospital. Twenty one children had concussion, 18 broke teeth, 53 fell head first over handlebars, and 131 had injuries above the neck. Significantly more children on ordinary cycles $(53 \%)$ had injuries above the neck than those on BMX cycles $(31 \%)$.

Difficulties and methods of preventing the increasing number of cycle accidents are discussed.

In a period of 60 consecutive days, starting on 2 July 1984, 300 children presented to the Accident and Emergency Department of the Children's Hospital, Sheffield after cycle accidents-almost $6 \%$ of the 5096 new attendances in the same period. A total of 169 of the $300(56 \%)$ had suffered accidents on ordinary bicycles and 131 on BMX bicycles ('Bicycle Motocross'). In a recently published series ${ }^{1}$ I described 100 consecutive accidents, on BMX cycles only, over a period of $\mathbf{4 0}$ days; apart from three patients attending on 2 July, at the beginning of the present series, there was no overlap.

This paper is intended to draw attention to the large and increasing number of accidents associated with all types of bicycles, and to compare the causes, clinical features, and severity of accidents on these two bicycles with a view to possible preventive measures.

\section{Method}

By means of a proforma we recorded the child's age; sex; type of bicycle; duration of ownership and of cycling experience; previous cycle accidents; place, cause, and nature of the accident; and the type of injury sustained. In those admitted to hospital the injuries were not graded until the final outcome was known. We listed the number of radiological studies and the proportion in which a fracture was found.
The severity of the injuries was roughly graded from 1 to 4 , as follows:

Grade 1. Injuries which were so trivial that no treatment or follow up was necessary.

Grade 2. This included minor lacerations and soft tissue injuries, bruises, and undisplaced fractures of fingers or toes.

Grade 3. This included the more serious lacerations, limb fractures that were undisplaced and for which admission was not required, minimally displaced greenstick fractures, and minor head injuries.

Grade 4. These were fractures for which admission was essential, seriously displaced fractures which needed a general anaesthetic for reduction, and head injuries with concussion (amnesia, reduced level of consciousness or persistent vomiting) or skull fracture, or both.

For convenience I have termed the two groups 'ordinary', meaning conventional bicycles, and BMX.

\section{Results}

Table 1 shows some of the details of the children. Seventy six of the ordinary group and $94 \%$ of the BMX group were boys. The mean age of the ordinary group was $91 / 4$ years, and of the BMX group 10 years. Both these differences were significant. 
There was no correlation between the age of the child and the severity of the injuries. Previous accidents, often multiple, were reported in $24 \%$ of the ordinary group and $40 \%$ of the BMX group (a significant difference), but these figures are probably an underestimate.

The 300 accidents included many serious injuries (Table 2), including two fractured skulls (one in each group) and 19 others with concussion-the incidence of which in the BMX group was almost double that in the ordinary group $(8.4 v 4.7 \%$; not significant). There were 38 other fractures (37 in limbs, one in the nose), and of the total of 40 fractures, significantly more $(60 \%)$ were in the

Table 1 Details of children involved in cycle accidents

\begin{tabular}{|c|c|c|c|}
\hline & $\begin{array}{l}\text { Ordinary } \\
\text { cycles* } \\
(n=169)\end{array}$ & $\begin{array}{l}B M X \\
\text { cyclest } \\
(n=131)\end{array}$ & Significance \\
\hline Age under 5 years & 10 & 4 & \\
\hline $5-9.9$ years & 43 & 37 & \\
\hline 10 years + & 47 & 59 & \\
\hline Boys & 76 & 94 & $P<0.01$ \\
\hline Accident Grade 2 & 50 & 48 & \\
\hline Grade 3 & 44 & 41 & NS \\
\hline Grade 4 & 6 & 11 & \\
\hline Admissions & $6 \cdot 5$ & $9 \cdot 9$ & NS \\
\hline Previous accidents & 24 & 40 & $\mathrm{P}<0.01$ \\
\hline Radiographs taken & 39 & 45 & NS \\
\hline Percentage showing fracture & 23 & 37 & NS \\
\hline
\end{tabular}

*Mean age $9 \cdot 25$ years. +Mean age $10 \cdot 0$ years; $\chi^{2}, P<0 \cdot 05$.

Table 2 Nature of injuries sustained

\begin{tabular}{llll}
\hline Injuries & Ordinary & BMX & Significance \\
& cycles & cycles & \\
& $(n=169)$ & $(n=131)$ & \\
& No (\%) & No (\%) & \\
\hline
\end{tabular}

\begin{tabular}{|c|c|c|c|c|c|}
\hline \multicolumn{6}{|l|}{$\begin{array}{l}\text { Above neck } \\
\text { Injuries above neck } \\
\text { (whether injury }\end{array}$} \\
\hline Fractured skull & 1 & - & 1 & - & \\
\hline Fractured nose & 1 & - & - & - & \\
\hline $\begin{array}{l}\text { Concussion } \\
\text { (without fracture) }\end{array}$ & 8 & $(4 \cdot 7)$ & 11 & $(8 \cdot 4)$ & NS \\
\hline Minor head injury & 30 & $(17 \cdot 8)$ & 14 & $(10 \cdot 7)$ & \\
\hline Tooth injury & $13^{*}$ & $(7 \cdot 7)$ & $5+$ & $(3.8)$ & \\
\hline Lacerations & 28 & $(16 \cdot 6)$ & 9 & $(6.9)$ & \\
\hline $\begin{array}{l}\text { Merely bruises, } \\
\text { abrasions above neck } \\
\text { Elsewhere }\end{array}$ & $12 \ddagger$ & $(7 \cdot 1)$ & $8 \S$ & $(6 \cdot 1)$ & \\
\hline Fracture in limb & $13^{* *}$ & $(7 \cdot 7)$ & $24+t$ & $(18 \cdot 3)$ & $P<0.01$ \\
\hline Sprains & 3 & - & 3 & - & \\
\hline Lacerations & 20 & $(11 \cdot 8)$ & 21 & $(16 \cdot 0)$ & \\
\hline or bruises & 47 & $(27 \cdot 8)$ & 39 & $(29 \cdot 8)$ & \\
\hline
\end{tabular}

*Includes 1 with minor head injury, 1 with nose injury; $\ddagger$ Includes 1 with concussion, 1 with minor head injury; łIncludes 3 with fractured limbs; \$Includes 2 with fractured limbs; ${ }^{* *}$ Includes 2 with minor head injury, 1 with abrasion of head; ++ Includes 1 with concussion, 1 with minor head injury, 3 with abrasions of head.
BMX group. Only six of the 34 children with a limb fracture were admitted to hospital. The proportion in grade 3 was almost the same in the two groups, but the proportion in grade 4 in the BMX group $(11 \%)$ was almost double that in the other group $(6 \%)$. There was a higher hospital admission rate in the BMX group $(9.9 \%)$ than in the ordinary group $(6.5 \%)$, but the difference was not significant.

Eighteen children had tooth injuries. A total of 131 children had injuries above the neckconcussion, minor head injury, fractures, tooth injuries, lacerations, bruises, or abrasions. The overall proportion of injuries above the neck was $53 \%$ in the ordinary group and $31 \%$ in the BMX group, a significant difference. Fifty three children (17\% and $18 \%$ respectively in the two groups) had a potentially dangerous accident when they fell head first over the handlebars. The figure in the previous BMX series was $23 \%$.

\section{How the accident happened}

We tried to elicit the exact details of each accident, but it was often impossible to be sure of the truth. In 21 children there was concussion and therefore some amnesia. Children may be reluctant, particularly in the presence of their parents, to tell the truth about their activities, their excessive speed, stunts, things done because of 'dares' by other children, failure to look, or even the use of drugs. Many children 'just fell off' without being able to explain why. There were no significant differences between the two groups with regard to the causes of the accidents, apart from stunts, and I have therefore combined them.

Fourteen children fell after striking an object on the road-stones, a brick, an apple, a tin, etc. Sixteen fell off after hitting a bump in the road or a drain hole. Fifteen collided with a wall, lamp post, or other fixed object. Eleven rode into a kerb (two slipped over the edge of a kerb) and seven rode into a parked car. Seventeen collided with other bicycles and 10 collided with or were hit by moving cars (in one case after the cyclist 'went through red lights'). Forty seven fell off after a skid-mostly on gravel, in some cases on a grassy slope, but in four of them after suddenly swerving to avoid an object or person. Thirteen fell off after slipping off a pedal, seat, or the handlebars and two fell off when changing gear.

Eight children were injured when a foot or finger caught in the spokes, pedal, or chain. One fell off when a plastic bag caught in the spokes. A 9 year old fell over the handlebars because when descending a hill he did not know where the brakes were. One fell because the bicycle was too big for him and a 
mentally subnormal child fell off for no known reason.

Many children fell because of doing silly things other than stunts. Eight fell off when sharing a bicycle with another child. One was pushed over by a girl, two fell off when stones were thrown at them, one was deliberately rammed by another bicycle and one fell when a boy put a stick into the spokes. Others fell off as a result of riding without a saddle, sitting on the handlebars, or sitting astride.

As one would expect, many more in the BMX group had accidents resulting from stunts (51 (39\%) compared with $18(11 \%)$ in the ordinary group) but five children in the ordinary group fell when performing a 'wheelie' (cycling on one wheel) and two fell on a ramp (compared with 13 in the BMX group). Two in the ordinary group fell when riding up steps. In both groups many fell while racing. In the BMX group children fell when performing 'wheelies', 'bunny hops', 'frame ups', or 'kerb endo' (getting over a kerb one wheel at a time), and three fell when riding backwards down a hill. Some fell when 'flying the whoop' (jumping over a bump on the track) or 'hitting the master camel' (jumping over two bumps at the same time).

Mechanical failures led to many accidents. Nine children claimed that they fell because of brake failure, and 14 because the brakes locked. We could not say whether they merely lost their balance by applying the brakes too suddenly and firmly. Five fell because a chain came off, two because the handlebars broke or came off, three because a wheel came off or buckled, and two because the pedals slipped off. Two claimed that the handlebars locked on turning. Almost all the remaining accidents were due to 'just falling off'-without excessive speed, racing, fooling, or other fault being admitted or recognised.

\section{Discussion}

There has been a notable recent increase in the number of cycle accidents presenting to this accident and emergency department, with 300 new cycle accident attendances in 60 consecutive days immediately after $100 \mathrm{BMX}$ accidents in the previous 40 days. $^{1}$ In 1981 I reported $^{2} 150$ bicycle accidents (on various types of bicycles) for comparison with injuries from other causes, but these 150 consecutive cases had occurred over a full six month period. Despite the popularity of BMX bicycles, $56 \%$ of the accidents were on ordinary bicycles. The high incidence of cycle accidents this year presented a large volume of work and necessitated 125 radiological studies, despite our constant aim to limit irradiation to a minimum.
In all cases we tried to obtain exact details of the nature of the accidents so that possible methods of prevention could be considered. Many of the factors such as the child's personality, play behaviour, racing, speeding, stunts, showing off, and normal aggression cannot be prevented, nor would it be desirable to try. Neither can one prevent objects lying on the road, nor irregularities on the road surface. The child's attention can, however, be drawn to the danger of drain holes in the path at home, and the danger of a coat or other object becoming caught in the spokes. But the provision of cycle lanes, as in Denmark and other countries, would help. Cycling proficiency classes run by the police to teach road sense, giving way at a junction, observing traffic lights, avoiding sudden changes of position on the road, care on emerging into a road, and the danger of cycling on the edge of a kerb (the source of several accidents in this series) can make a useful contribution. The courses should also include proper maintenance of the chain, gear, and brakes. Some excellent classes already exist but most are for older children. It seems important that the many younger children riding bicycles should be offered proper training as early as possible. There are some BMX clubs that give supervised instruction, but few of the children riding $\mathrm{BMX}$ bicycles belong to them. It is notable that 18 of the BMX accidents were said to have occurred on BMX tracks.

Children should be discouraged from riding with a second child on the bicycle. Eight accidents in this series resulted from this, and in an Australian series, ${ }^{3} 23$ of 139 accidents were ascribed to 'doubling'.

Parents should give thought to the type of bicycle they buy for a child or allow him to ride. Some of the accidents were due to the bicycle being too big. Many were due to unfamiliarity with the machine. In 16 cases (11 of them on a BMX) the accident occurred within a month of purchase-in several cases within two or three days. The particular dangers of 'high rise' cycles were described a few years ago. ${ }^{45}$

BMX clubs make sure that protective clothing is worn but in this series only two of the BMX riders had used any. A hundred and thirteen of the 300 children in this series had injuries above the neck that were potentially hazardous. Skull fracture and brain injury without fracture were the most common causes of death in cyclists between 5 and 14 years in 78 of 100 deaths in 1979 and 46 of 65 deaths in $1982 .^{6}$ Many of these deaths might have been prevented if proper head protection had been worn and efforts should be made to persuade all cyclists (BMX and other) to use safety helmets.

Non-slip pedals, saddles, and handlebar grips 
would help. Thirteen of the accidents in this series were due to the child's foot, hands, or seat slipping.

Safety films in schools and youth clubs showing the causes of accidents, the results of skidding and collisions, of objects being caught in the spokes, and the other causes mentioned above would be useful.

Finally we have no information about the relevance of drugs such as tranquillisers when taken by children or how many young 'solvent sniffers' ride bicycles. It is well known that cannabis ${ }^{7}$ increases the risk of road traffic accidents. It would be reasonable to investigate this but difficult to establish the truth.

Cycling is increasing in popularity with all age groups and as much as possible should be done to prevent accidents to the large numbers of children who ride all types of bicycles.

I thank all the members of the junior medical staff of the Paediatric Accident and Emergency Department, Children's Hospital, Shef- ficld for their help in collecting the information for this series. I also thank Professor John Knowelden for his statistical help.

\section{References}

1 Illingworth $\mathrm{CM}$. Injuries in children riding BMX bikes. $\mathrm{Br}$ Med J 1984;ii:956-7.

2 Illingworth CM, Noble D. Bell D, Kemm I, Roche C, Pascoe J. 150 Bicycle injuries in children: comparison with accidents due to other causes. Injury 1981;13:7-9.

${ }^{3}$ Gonski L, Southcombe W, Cohen D. Bicycle accidents in childhood. Med J Aust 1979:2:270-1.

${ }^{4}$ Croft AW, Shaw DA, Cartlidge NE. Bicycle injuries in children. Br Med J 1973;iv:146-7.

5 Sibert JR, Newcombe RG. Bicycle injuries in children. $\mathrm{Br}$ Med J 1977;i:613-4.

- Office of Population Censuses and Surveys. Mortality statistics accidents and violence. Series DH 4 nos 6 and 8. London: HMSO 1982.

${ }^{7}$ Committee on drugs. Marijuana. Pediatrics 1980;65:652-6.

Correspondence to Dr C Illingworth, Accident and Emergency Department, Children's Hospital, Sheffield S10 2TH.

Received 14 January 1985 